\title{
Determining the Life Cycle Phase of a Technology Based on Patent Data
}

\author{
Vladimir SMOJVER, Mario ŠTORGA, Eva POTOČKI
}

\begin{abstract}
Developing new technologies is one of the most important goals of today's scientific and industrial research. Understanding how technology evolves, as well as its current state, is invaluable in an ecosystem where technology is evolving at an increasingly rapid pace. In this paper, patent data is used to determine a technology's life cycle. Two patent maps are created, one based on patent citations and one based on keywords. The citation patent map visualizes how patents cite each other, while the keyword patent maps visualize keywords used to describe patents and their relations. Both of these patent maps are dynamic, meaning they change over time thus giving insight into an examined technology's evolution. A growth analysis of both networks is conducted as well as a degree distribution analysis. Both of these analyses are used to help determine the technology's lifecycle phase as well as its patterns of growth. This insight is invaluable to stakeholders tasked to make strategic decisions related to technology development.
\end{abstract}

Keywords: Life Cycle Analysis; patent analysis; tech mining; technology evolution

\section{INTRODUCTION}

Understanding how technology evolves is important in both industrial and academic research. In an academic context, insights into the nature of technology evolution can provide additional value for the fields of technology and innovation management, design theory, risk management etc. In an industrial context, this understanding is invaluable to stakeholders at different levels tasked with making decisions related to the development or implementation of technology, both on a project and strategic level. Organizations operating in highly competitive market conditions have a need to up-todate knowledge about emerging and disruptive technologies [1], as well as the current state of established technologies, in order to properly plan the introduction of new products and services or improvements of existing ones into the market. According to Joung et al. [2] emerging technologies pass through three stages: 1) Pre emergence, where a technology has a high level of radical novelty and uncertainty but low levels of growth rate; 2) Emergence, where the technology shows moderate relatively fast growth, coherence a prominent impact; and 3) Post-emergence, where the technology reaches low levels of radical novelty and uncertainty. An attribute of technology, whose understanding is important to facilitate understanding the technologies' evolution, is the Technology Life Cycle (TLC) phase, which measures technological changes and includes two dimensions: the competitive impact and integration in the products or process, and also consists of four stages [3]. Understanding what phase of its life cycle a technology is in enables stakeholders to examine whether the said technology is eligible for further investing in or research and development.

In the research presented in this paper, patents are used as proxies for technological invention. Patent data is the primary data source for studying how a technology evolves and examining its life cycle in the particular technology field. In looking at the dynamics of the technologies evolution, patent citations are examined as well as the keywords used in describing the inventions within patent claims. The rest of the paper is structured as follows: Section 2 provides a literature review encompassing basic patent theory relevant to the research as well as a review of the state of the art of the citation and keyword based models as well as models of technology evolution. Section 3 describes the methodology used in the research. Section 4 presents the case study and the results of the application of the methodology. Section 5 presents a discussion of the results of the case study while Section 6 provides a conclusion.

\section{LITERATURE REVIEW \\ 2.1 Technology Evolution Models}

Understanding the theory of technology innovation and development is crucial in order to model the technologies' evolution as well as to identify which phases of product invention and development the results of this research can be applied to. Two main theories of technology evolution exist in the literature. The first one is the theory that technology evolves incrementally, meaning the evolution of technology is a series of incremental improvements that accrue over time and result in technological advances [4]. An incremental new product generally involves the adaptation, refinement, and enhancement of existing products [5]. The second theory proposes that a technology evolves in a continuous cycle of stagnation and radical improvements, meaning a technology improves by introducing a radical improvement that is followed by a period of relative stagnations. These periods of stagnation are then broken with the introduction of new radical innovations. These differences are explored by Holahan et al. [6] who explore the differences in the development of incremental, innovative and radical products types with respect to formal product development practices, project organization, strategy, and other influences. Another important concept when discussing technology evolution is the emergence of disruptive innovations. A disruptive innovation is an innovation that creates a new market and value network and eventually disrupts an existing market and values network, displacing established market-leading firms, products and alliances [7]. Although the terms "radical" innovations and "disruptive" innovation are often used interchangeably, it is often not the case that a disruptive innovation is radical and vice versa. An 
overview of research sees all of these types of evolution modeled using patent data. $[3,8,9]$

\subsection{Elements of Patent Applications}

A patent is "an exclusive right granted for an invention, which is a product or a process that provides, in general, a new way of doing something, or offers a new technical solution to a problem" (http://www.wipo.int/patents/en/). Based on this definition, it is clear that patents can be used as proxies for inventions in the modeling of technology evolution. The information contained in the patent applications are: 1) Bibliographic data, consisting of the Title, Inventor, Owner... 2) Relevant background art; 3) Disclosure of the invention, a clear and complete written description of the patent; 4) Claims, defining what is sought to be protected; 5) Abstract, giving a brief overview of the invention and 6) Prior art of relevance to the invention.

Patents also contain classification codes which provide for a hierarchical system of language independent symbols for the classification of patents and utility models according to the different areas of technology to which they pertain. These classification codes differ in different patent offices, although a new classification code (CPC) has recently been introduced which should harmonize the patent classification system between the European Patent Office and the US Patent Office. In the presented research, two patent attributes were used. The first one, patent citations, contains information about the patents that the examined patents cite as well as those patents that cite the examined patents. This information is interesting because it shows how knowledge transfers from invention to invention. The second is the patent claim. This claim consists of a description that can be analyzed using text analysis methods and tools to extract keywords describing the patent topic.

\subsection{Patent Citation Maps}

Patent claims contain information about relevant patent citations, both forward and backward. When a patent is cited by other patent applications, those citations are called forward citations [10]. Backward citations are the patents (and other sources) that the examined patent cites. Analysis of these citations can provide insight into how a technology field evolves, how knowledge diffuses, etc. Several authors use patent information to gain insight into a technologies life cycle. Haupt et al. [11] identify several patent indices as appropriate life cycle stage indicators, among them forward and backward citations. Gao et al. [3] conduct similar research, building a model to calculate the TLC for a technology based on patent-related indicators. Altuntas et al. [12] devise a method for forecasting technology success based on patent data using life cycle analysis. Kayal [9] introduces metrics that measure the pace of technology progress called the Technology Cycle time (TCT) indicator. Yoon et al. [13] propose network analysis methods for analyzing citation networks. They introduce the technology centrality index, technology cycle index and technology keyword clusters for an in-depth quantitative analysis of the network, identifying trends of high technologies and promising avenues for new product development (NPD). A similar network analysis is conducted by Leeet al. [14] using network properties to calculate technology evolution mechanisms with the aim of identifying critical patents. Chen et al. [15] focus on detecting communities within the patent network and tracking their growth over time, then evaluating which network properties predict long-term growth of the communities.

Table 1 Literature review of patent citation-based approaches

\begin{tabular}{|l|l|l|}
\hline \multicolumn{1}{|c|}{ Author } & \multicolumn{1}{|c|}{ Method } & \multicolumn{1}{c|}{ Output } \\
\hline Haupt et al. & Multiple indicators & Life cycle stage \\
\hline Gao et al. & Multiple indicators & Life cycle stage \\
\hline Altuntas et al. & $\begin{array}{l}\text { Cumulative number of } \\
\text { patents }\end{array}$ & Life cycle stage \\
\hline Kayal & $\begin{array}{l}\text { Technology Cycle Time } \\
\text { Indicator }\end{array}$ & $\begin{array}{l}\text { The pace of } \\
\text { technological progress }\end{array}$ \\
\hline Yoon et al. & Social network indexes & $\begin{array}{l}\text { Trends of technologies } \\
\text { and avenues for NPD }\end{array}$ \\
\hline Lee et al. & Social network properties & $\begin{array}{l}\text { Technology evolution } \\
\text { insight }\end{array}$ \\
\hline Chen et al. & $\begin{array}{l}\text { Detecting communities } \\
\text { and tracking growth over } \\
\text { time }\end{array}$ & Prediction of growth \\
\hline
\end{tabular}

\subsection{Patent Keyword Maps}

Patent claim text defines the scope of protection the patent grants. Text analysis methods (for example Natural Language Processors (NLP)) can be employed to analyze claims and extract keywords pertinent to the invention and the related technology area. Tseng et al. [16] present a series of text mining methods that conform to the analytical process used by patent analysts. Lee et al. [17] propose an approach for creating and utilizing keyword-based patent maps for use in new technology creation activity. Joung et al. [2] present a method for keyword-based patent analysis with the goal of monitoring emerging technologies.

Table 2 Literature review of keyword-based approaches

\begin{tabular}{|l|l|l|}
\hline \multicolumn{1}{|c|}{ Author } & \multicolumn{1}{|c|}{ Method } & \multicolumn{1}{c|}{ Output } \\
\hline Tseng et al & Text mining & $\begin{array}{l}\text { Patent map for topic } \\
\text { analysis }\end{array}$ \\
\hline Lee et al. & Text mining & $\begin{array}{l}\text { Patent vacancies are } \\
\text { identified }\end{array}$ \\
\hline Joung et al. & $\begin{array}{l}\text { Keyword context matrix; } \\
\text { hierarchical clustering }\end{array}$ & $\begin{array}{l}\text { Monitoring of emerging } \\
\text { technologies }\end{array}$ \\
\hline Choe et al. & $\begin{array}{l}\text { Bayesian clustering, } \\
\text { principal component } \\
\text { analysis }\end{array}$ & $\begin{array}{l}\text { Vacant Technology } \\
\text { Forecasting }\end{array}$ \\
\hline Jun et al. & Bayesian clustering & Technology trends \\
\hline
\end{tabular}

Kim et al. [18] use the K-means algorithm to cluster patent documents using collected keywords from a targeted technology field. Choe et al. [19] present a method for identifying vacancies in an examined industrial field called Vacant Technology Forecasting using Bayesian clustering of patents. Jun et al. [20] also propose a Bayesian clustering method for analyzing data extracted from patents.

\section{RESEARCH METHODOLOGY}

The aim of the methodology applied in this research is to determine the lifecycle phase of a technology based on an analysis conducted on patent applications and examine its evolution as well as identify patterns in the evolution of a technology and how they relate to patent data. There are several steps of the proposed methodology (Fig. 1). The 
first step is the selection of the technology to be analyzed and retrieval of the relevant patents. The relevant patents should be identified using a combination of keywords and IPC (International Patent Classification) classification codes. The key information for the analysis should be structured and a dataset for the analysis should be created. The dataset should contain the following information about the patents: Patent title, Publication date (or application date), Citations, Claims, and Classification Codes.

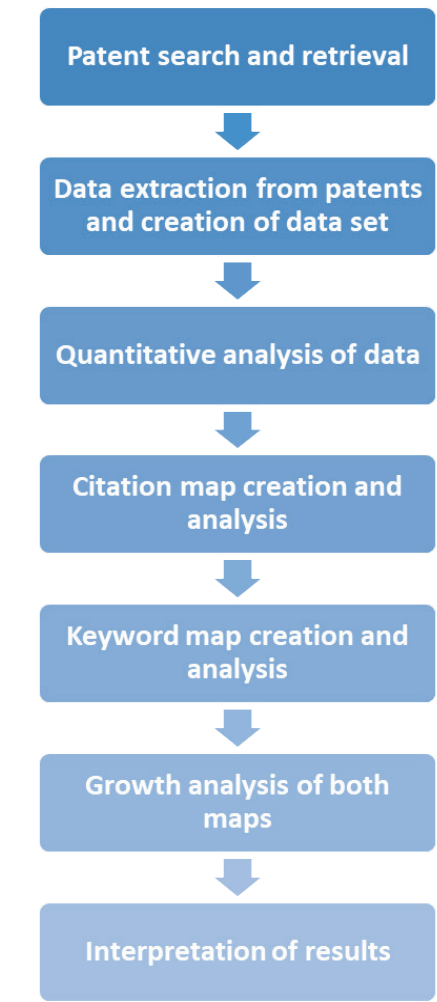

Figure 1 Overview of the research methodology

The next step after dataset creation is a quantitative analysis of the yearly patent applications since the inception of the technology field. The year of the technologies field inception is determined by the year the first patent from that field was applied. This metric is one of the metrics that provide insight into the dynamic of how a technology field evolved over time. Other metrics can be found in literature but are not incorporated in this research $[21,22,9]$ and provide a wide range of insight into a technology field including, but not limited to, breadth of technology field, key companies in the technology field, rate of development, influence on and from other technology fields etc.

This is followed by creating a patent map using patent citations. This map is a directed graph where nodes represent patents and edges represent citations. A directed edge between patent $\mathrm{A}$ and patent $\mathrm{B}$ means that patent $\mathrm{B}$ cites patent $\mathrm{A}$. If considered dynamically, it illustrates the transfer of knowledge between the patent applications over time. The fifth step is the creation of the keyword based patent map. The keywords are used to track the evolution of knowledge contained within patents. The analysis of the keywords contained in patents enables the identification of technology elements utilized in patents at a certain point in time and augments the understanding of which technologies contributed to the development of the

technology field. Finally, an analysis of network growth dynamics for citation and knowledge graph should be applied in order to gain insight into trends in evolution. The final step is the interpretation of the results.

\section{CASE STUDY}

As a case study, the technology field of safety ski bindings was selected. The technology is classified under the IPC classification code A63C9/08. The technology of safety ski bindings was chosen because it is a known mature technology which has not seen much innovation in recent time. Therefore, it is a technology empirically identified as being in the fourth stage of its life cycle, saturation. This knowledge enabled us to more easily validate the results of our analysis.

The dataset for the ski bindings was retrieved in the following way. First, the selected patent database (Google Patents) was searched using keywords related to the technology, "safety ski bindings". This database was chosen because of its openness and because it covers all relevant jurisdictions, among other advantages. The results of the search were examined and the IPC code most used to categorize the patents in the results was identified. Then, a second search was conducted, this time using the classification code as an input, and all results were retrieved. Finally, all of the results of the second search were manually cross-checked to ensure that the retrieved patents relate to the targeted technology. In total, 547 patents were retrieved. It should be noted that manual retrieval is not practical for technology fields consisting of large numbers of patents. Patent retrieval in future work will be done using an automatic or semi-automatic method.

\begin{tabular}{|l|c|} 
Table 3 Retrieved data set \\
\begin{tabular}{|l|c|}
\hline Name of Technology: & Safety ski bindings \\
\hline IPC Code: & A63C $9 / 08$ \\
\hline Number of retrieved patents: & 547 \\
\hline Total number of citations: & 3850 \\
\hline
\end{tabular}
\end{tabular}

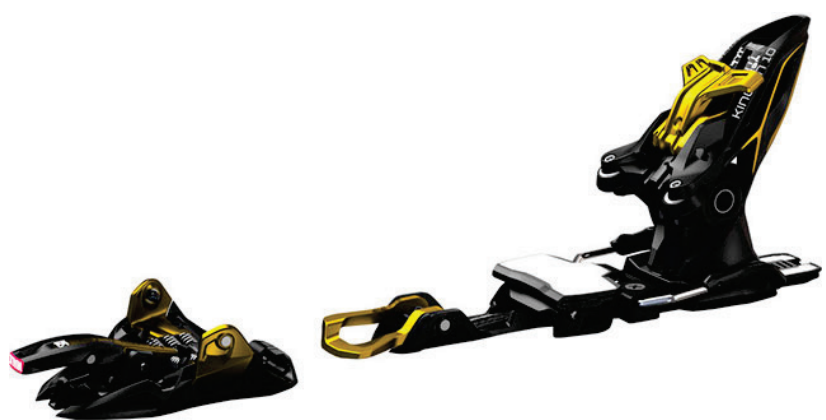

Figure 2 Safety ski binding

\subsection{Safety Ski Bindings}

Safety ski bindings are devices that connect the ski boot to the ski. They are called "safety" ski binds because they release the boot in case of a load that might cause injury to the user (e.g. a fall). The first safety binding was introduced to the market in 1939 by Hjalmar Hvam, a Norwegian skier, inspired by a skiing injury he sustained a few years earlier [23]. The first patent for safety ski binding, a toe unit that would release in all directions, was introduced in 1951 by Mitch Cubberley (US2573955A). It should be noted that this patent is not included in our 
dataset since we chose 1960 as the starting year of our model considering the number of patents applied from 1952 to 1960 is very low.

\subsection{Example of Quantitative Analysis - Understanding Evolution Performance}

As an example of the quantitative analysis, the number of patents granted since the inception of the technology field (1951), is examined (Fig. 3). When a chart is created illustrating the cumulative number of patents issued up to a certain year, it is possible to recognize the generated curve approximates an S-curve. From this chart, it is possible to clearly identify the 4 phases of the technology life cycle: initiation (1951-1968), growth (1969-1975), maturation (1976-1978) and saturation (1976-2015).

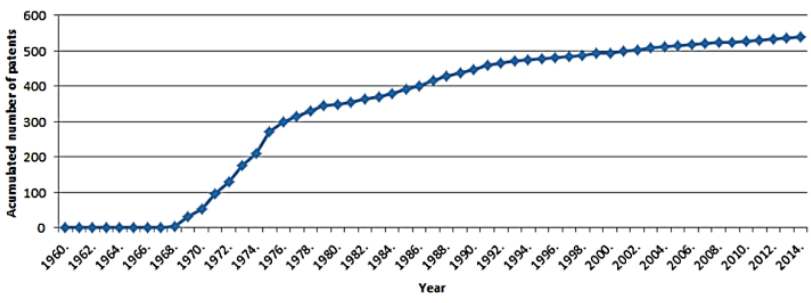

Figure 3 S-Curve of safety ski binding technology patents growth [21]

As mentioned in the literature review, other quantitative metrics can be applied on the data set in order to gain insight into a technology's evolution (an example of other metrics being applied to the data set is demonstrated in the author's previous work, [21]). However, these metrics go out of the scope of determining a technology's life cycle so they are not applied in this work.

\subsection{Citation-Based Patent Map}

For the purpose of this study, a patent citation network was first generated and dynamically analyzed after every new patent was added to the network. The applied approach is partially based on the work of Cash et al. [24]. The nodes within the network represent patents while the edges represent citations. Since the network topology and properties are changing at every time point that a new node is added, the evolution of the technology can be observed as a series of discrete time points or it can be visualized as an animation. Community detection was applied dynamically to analyze the close groups of the patents and understand the evolution. In Fig. 4, the state of the technology at time points corresponding to the end of each TLC phase is represented.

The size of the nodes represents the node degree as the main measure of the ingoing and outgoing edges for each node. When analyzing the citation network, star-shaped communities could be spotted meaning that a smaller number of technologies within each community have an above-average number of edges compared to the rest of the network. This can be interpreted as an indicator that technology evolution was influenced by a popularity bias (i.e. nodes representing patents with more citations had a higher probability of new citation) [25].
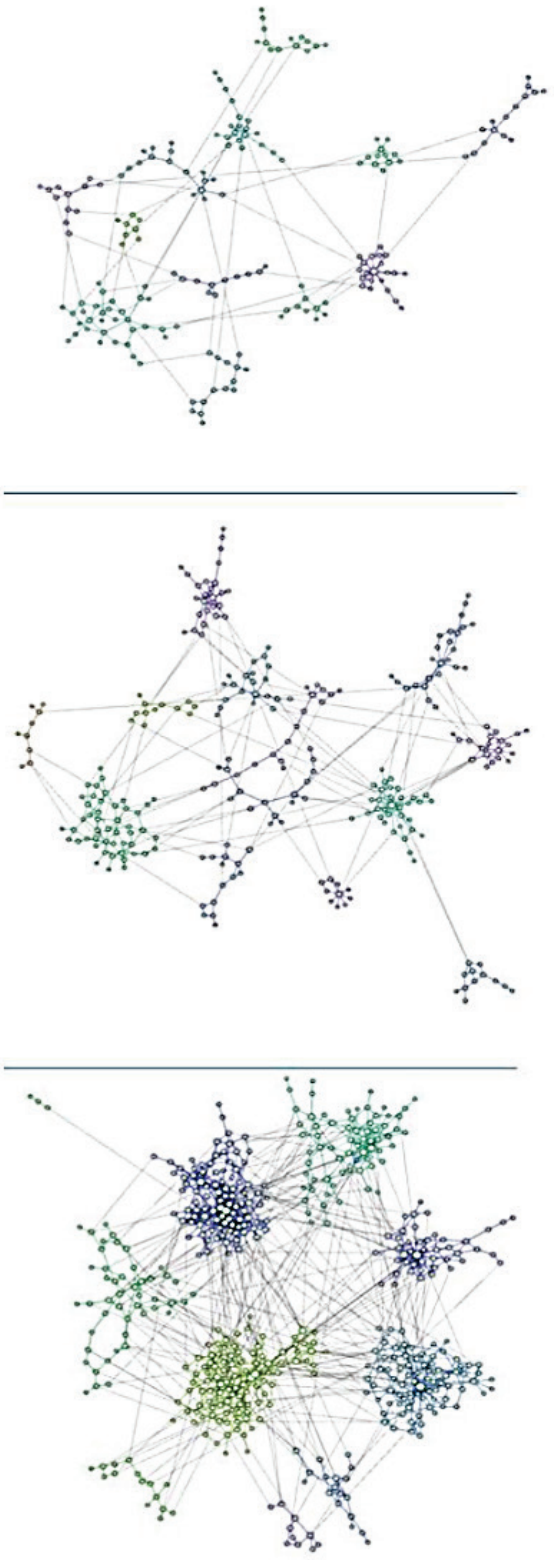

Figure 4 Evolution of the patent citation network for ski bindings depicted by network configuration after key TLC phases (growth - 1975, maturation - 1978, saturation - 2015) [21]

\subsection{Keyword-Based Patent Map and Network Growth Analysis}

The second network created was a keyword based patent map. This keyword map was built as a graph of the nodes representing keywords extracted from the patent claims using an NLP tool. In the presented research, the keywords were extracted from the patent claims contained in the data set using the NLP (Natural Language Processing) tool Alchemy API. The filtering and normalization of the extracted keywords was done manually. A keyword-based network was created applying the rule that if two keywords (represented as nodes within the network) were extracted from the same patents, an edge should be created between them. As for the citation map, the network was analyzed dynamically and community detection was applied during that process (Fig. 5).

Examining and analyzing keyword based patent maps enables a better understanding of what technologies contributed to the development of the technology field. 
When interpreting the results of the keyword map at any given time point the lifecycle phase of the technology, as identified in 4.2, was taken into account. At the end of the initiation phase, there are only a few patents which do not share keywords. Therefore, there are no edges between keywords from different patents. The growth phase shows a large increase in the number of keywords as well as the number of edges and first communities are being created.

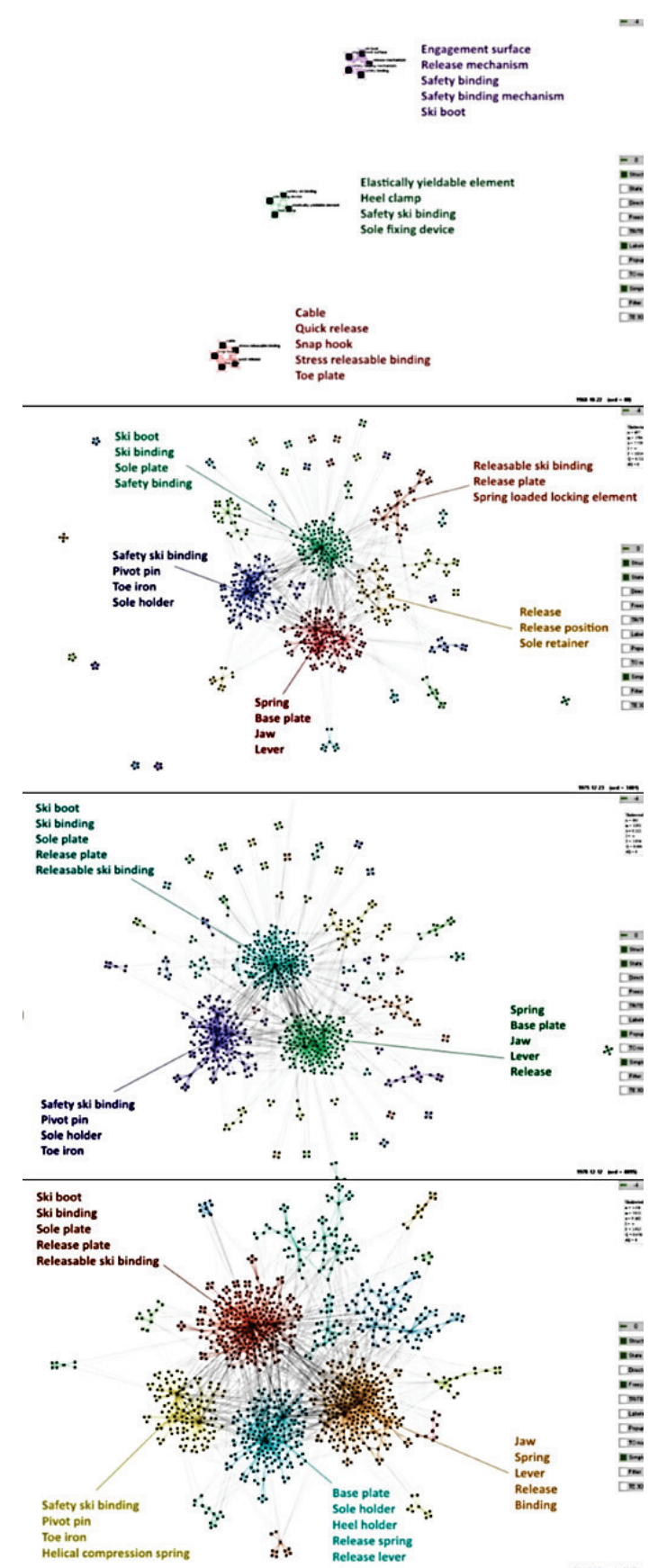

Figure 5 Evolution of the keyword network for ski bindings depicted by network configuration after key TLC phases

As in the citation based patent map, communities form a star-shaped pattern, demonstrating the existence of a popularity bias (existing keywords had more probability to be reused again). During the last two phases, maturation and saturation, the keyword graph can be seen becoming denser and restructured. The number of edges keeps increasing while the number of nodes evens out. Another part of the keyword analysis consists of labeling a cluster of keywords as a thematic topic and analyzing the evolution of these topics. Fig. 6 shows the assigned topics and the occurrence over time.

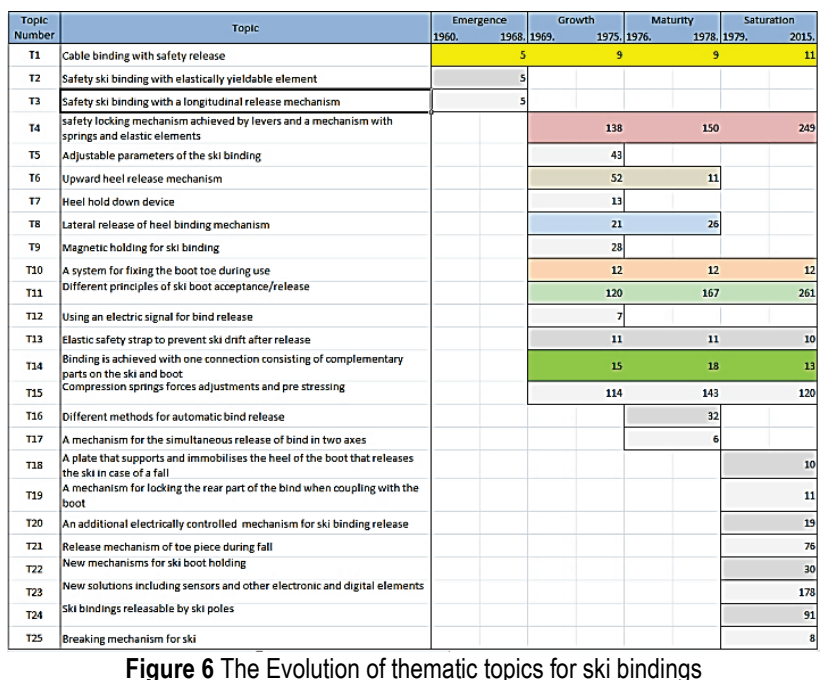

Tn denotes the topic marked with the ordinal number $n$. This coding of topics was done in order to make the analysis simpler. The numbers on the timeline at the end of every LC phase show the number of keywords the respected topic contains at that moment. This visualization enables a clear overview of technologies thematic evolution.

\subsection{Citation and Knowledge Network Growth Analysis}

Both generated networks were subjected to a degree distribution and growth analysis. The degree distribution was created based on the work of Powell et al. [25] who describe different types of network nodes' degree distribution which can be distinguished when plotted on a $\log$-log scale. In Fig. 7, the abscissa represents the node degree $\mathrm{D}$, aggregated over the overall time period of the study. The ordinate represents the number of patents having a degree $\mathrm{N}$, also aggregated. The light grey line represents the logarithmic distribution of the nodes per the degrees while the dark blue segmented line represents the same within the bins of degrees being normalized to grow exponentially and the black line represents the trend line linear approximation for the normalized distribution.

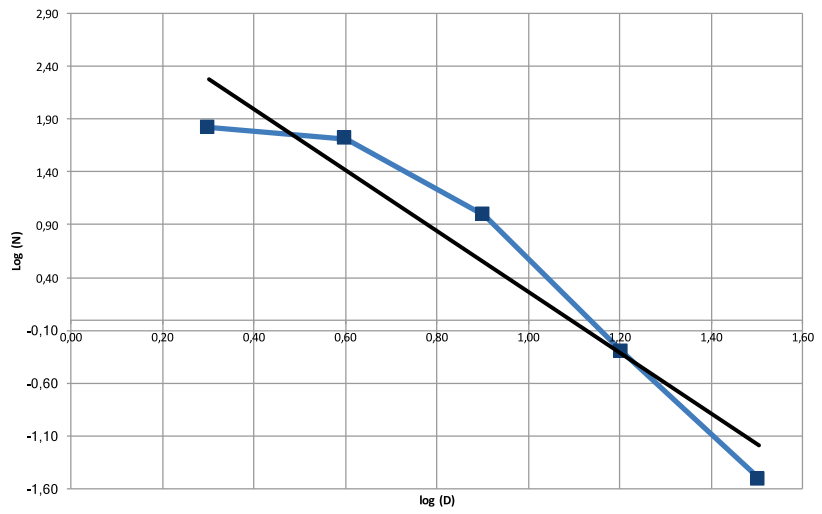

Figure 7 Degree distribution of patent citation network 
From Fig. 8 it can be deduced that the nodes in both maps are governed by a popularity bias. In the citation network, this means that patents exist which can be considered key inventions which influence a large number of subsequent inventions. For the keyword network, the same analysis degree distribution analysis is conducted. From Fig. 8 it can be deduced that the nodes in the keyword patent maps are governed by a random bias distribution based on the convex shape of the trend line approximation.

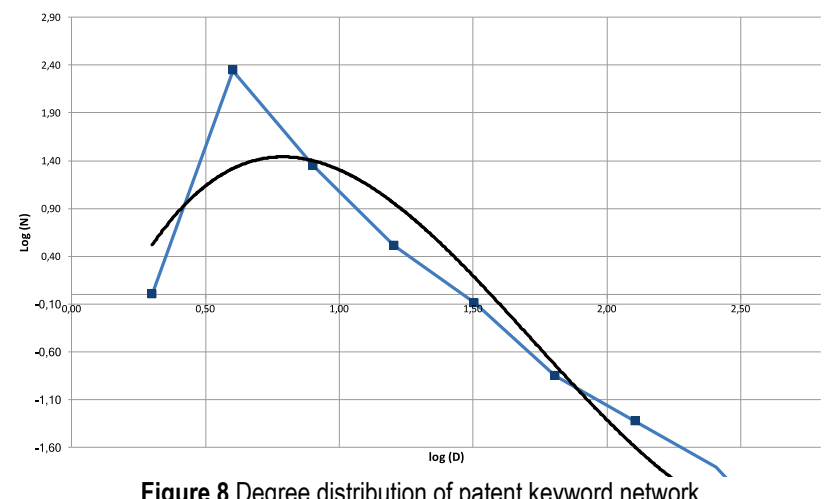

Using a method proposed by Cash et al. [24] a growth analysis is performed on both networks. This analysis gives insight into the network formation and growth dynamics and enables the identification of different growth phases of the network. A positive trend in the growth analysis corresponds to a phase where more nodes than edges are added to a network. A negative trend corresponds to a phase where more edges than nodes are being added. The abscissa represents a time index in the evolution of the network while the ordinate represents the rate of growth denoted by $\delta$.

The results of the growth analysis applied to the patent citation network are shown in Fig. 9. During the growth phase, more new patents are introduced then citations are made resulting in a constant growth of the patent network structure. In the maturation phase, the number of new patents introduced is roughly equal to the number of citations being made resulting in a mostly neutral trend. In the saturation phase, more citations are being made than new patents introduced resulting in a negative trend of network growth. These results can be explained intuitively. During the growth phase of a technology field, more novel inventions are being introduced resulting in patents. As a field stagnates, new inventions are more often the results of the recombination of existing technologies, resulting in a relatively larger number of citations.

Fig. 10 shows the results of a network growth analysis where the keyword network is generated and continuously recalculated whenever a new keyword is added. The phases of the technology's life cycle are denoted by a red line. In the first phase, more new keywords than patents are added to the network, meaning new patents generally introduce new keywords and a positive network growth is observed. In the second and third phase, more patents than keywords are added to the network causing a negative network growth rate. This means that inventions in the later stages of a technology's life cycle mostly recombine existing technologies. This is consistent with the results of citation patent network growth analysis. It should be noted that, even in the stagnation phase of the technology's life cycle, peaks occur (at around $73 \%$ and $87 \%$ if total lifetime) which denote the appearance of innovative patents introducing new keywords. These new technologies prove influential in developing the field.
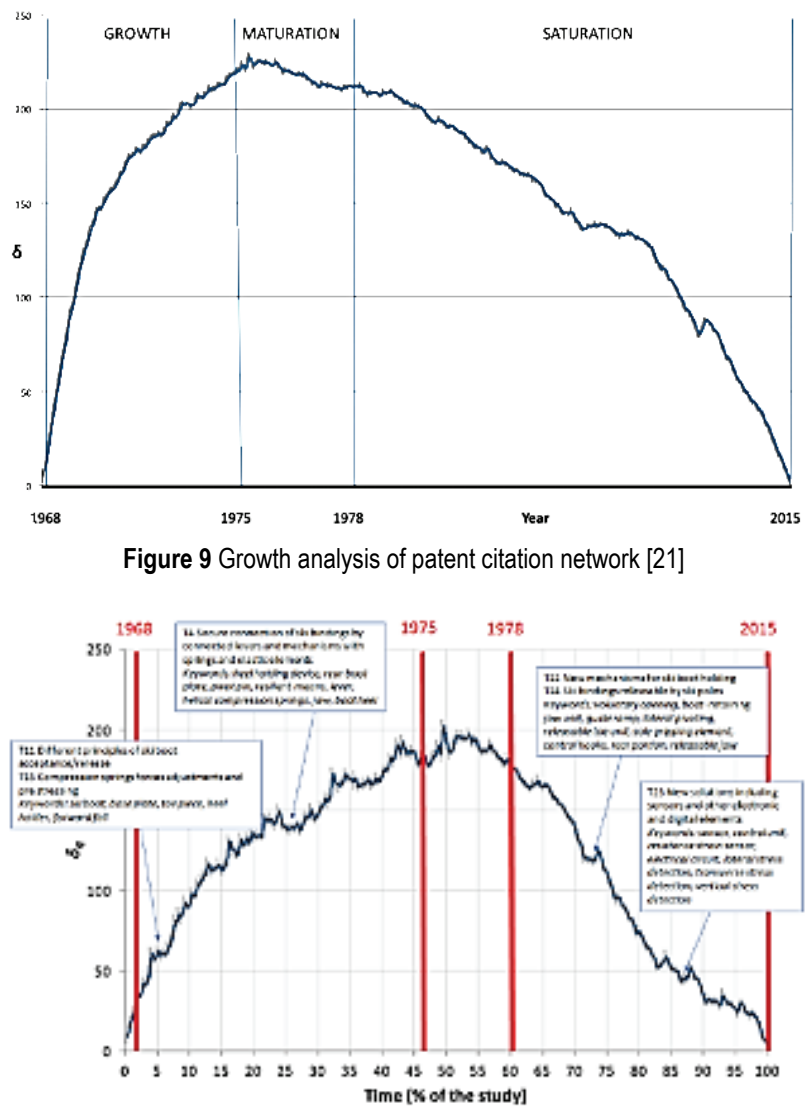

Figure 10 Growth analysis of patent keyword network

\section{DISCUSSION}

In the case study presented, three quantitative metrics are applied to a set of retrieved patents with the goal of improving the understanding of the evolution of an examined technology as well as its life cycle. These metrics are: 1) The cumulative number of patents applied over time, 2) The growth analysis of a citation based patent map, and 3) The growth analysis of a keyword-based patent map.

The first quantitative analysis, examination of the cumulative number of patents applied, confirms the findings of previous research which claimed that the number of cumulative patent applications plotted over time follows an S-curve with discernible life cycle phases [12, 3]. However, this method is imprecise and can only be used to gain an approximate overview of a technologies life cycle. Moreover, if the technology examined is not in its final lifecycle phase the S-curve pattern is not clearly visible which makes identifying a technology's life cycle phase more difficult.

The second quantitative analysis applies the growth analysis [26] on a patent map generated by using citation data. While citation data has been used to determine the life cycle stage of a technology, it was generally based on examining the number of forward and backward citations and how they change over time [11]. This research takes a new approach, taking into account both the number of 
citations and the number of patents over time, examining them both dynamically. The result of this analysis shows that the rate of growth increases from 1968 to 1975, representing the growth phase of a life cycle, starts to stagnate from 1975 to 1978 , representing the maturation phase and finally starts decreasing from 1978 to 2015 representing saturation. Based on these time periods we can determine the approximate boundary years of life cycle phases. The life cycle phases determined by this analysis coincide with those inferred from the first quantitative analysis.

The third quantitative analysis consists of a growth analysis of a patent map generated from keywords extracted from patent applications and a topic evolutions analysis is conducted. Using this method, researchers can examine and gain insight into how a technology evolves over time as well as how technology diffuses between new inventions. The results from the growth analysis of the keyword based method coincide with those from the second quantitative analysis. The growth analysis of the keyword network shows almost identical technology life cycle phases. This tells us that the patents introduced in the growth and maturation phase introduce new knowledge and technologies while the patents in the saturation phase mostly reuse and recombine old knowledge. This is in line with the research of Joung et al. [2] and their claims about the three stages of emerging technology stages.

Both of the generated networks, citation, and keyword, were submitted to a degree distribution analysis with the goal of understanding the nature of network growth. This is a novel approach in describing the dynamic of technology evolution. The results of this analysis show that the citation network is governed by a popularity bias while the keyword network is governed by a random bias distribution.

The fact that three methods roughly identify the same life cycle phases increases the validity of the results while at the same time the information provided by the method complement each other in understanding the technology and its evolution.

If validated on a significant number of cases, some of the insights gained from this research, namely the way technology elements defuse over time as well as how key patents influence new inventions, might start to be considered as a rule and become important elements in understanding how a technology evolves.

\section{CONCLUSION}

In this paper, the authors present a method of exploring and analyzing a technology's life cycle. Using patent data as a data source, we explore the life cycle of safety ski bindings. Three approaches are applied to this analysis. First, a quantitative analysis of the number and history of patent applications over time is made and visualized. Then, a patent map based on patent citations is created and analyzed. Another patent map based on keywords extracted from patent text is also created. A growth analysis, as well as a distribution analysis, is made of the generated patent maps with the goal of identifying the technology lifecycle phase as well as identifying certain rules governing the technology's evolution. We identify the technology as being in its stagnation phase. We also identify that technology evolution is influenced by popularity bias, meaning that technologies which at one point in time have a higher than an average number of citations have a better chance of gaining more citations. Future work should introduce more models for analyzing both the citation and keyword network with the goal of deepening our understanding of technology evolution. Moreover, an improved methodology for searching and retrieving patents from databases should be employed, ensuring a higher quality of data sets. Finally, current research should be expanded with prediction models for forecasting the future evolution of a technology based on its past evolution. Potential drawbacks of this research should be mentioned as well. The most common criticism of method that utilizes patents as a primary data source is the fact that not all inventions are patented therefore the retrieved data set does not represent the entirety of knowledge for the examined technology. While the claim that not all inventions are patented is true, a large majority are, allowing for the identification of trends. Moreover, this research examines how technology evolves in the context of patents as proxies of technology. Therefore, it is assumed that an invention not patented is not generally available so it does not influence subsequent inventions and consequently is not part of their evolution chain.

\section{Acknowledgments}

This paper reports work funded by the Croatian Science Foundation Team Adaptability for InnovationOriented Product Development (TAIDE) project (www.taide.org) and the Center for Vehicles of Croatia (CVH).

\section{REFERENCES}

[1] Dedehayir, O., Nokelainen, T., \& Mäkinen, S. J. (2014). Disruptive innovations in complex product systems industries: A case study. Journal of Engineering and Technology Management - JET-M, 33, 174-192. https://doi.org/10.1016/j.jengtecman.2014.06.002

[2] Joung, J. \& Kim, K. (2016). Monitoring emerging technologies for technology planning using technical keyword based analysis from patent data. Technological Forecasting and Social Change. https://doi.org/10.1016/j.techfore.2016.08.020

[3] Gao, L., Porter, A. L., Wang, J., Fang, S., Zhang, X., Ma, T., ... Huang, L. (2013). Technology life cycle analysis method based on patent documents. Technological Forecasting and Social Change, 80(3), 398-407. https://doi.org/10.1016/j.techfore.2012.10.003

[4] Sood, A., James, G. M., Tellis, G. J., \& Zhu, J. (2012). Predicting the Path of Technological Innovation: SAW vs. Moore, Bass, Gompertz, and Kryder. Marketing Science, 31(6), 964-979. https://doi.org/10.1287/mksc.1120.0739

[5] Song, X. M. \& Montoya-Weiss, M. M. (1998). Critical development activities for really new versus incremental products. Journal of Product Innovation Management, 15(97), 124-135. https://doi.org/10.1016/S0737-6782(97)00077-5

[6] Holahan, P. J., Sullivan, Z. Z., \& Markham, S. K. (2014). Product development as core competence: How formal product development practices differ for radical, more innovative, and incremental product innovations. Journal of Product Innovation Management, 31(2), 329-345. https://doi.org/10.1111/jpim.12098 
[7] Christensen, C. M. (1997). The innovator's dilemma. Harvard Business School Press, Boston, 1-179. Retrieved from http://scholar.google.com/scholar?hl=en\&btnG= Search\&q=intitle:The+Innovator?s+Dilemma\#4

[8] Altuntas, S. \& Dereli, T. (2015). A novel approach based on DEMATEL method and patent citation analysis for prioritizing a portfolio of investment projects. Expert Systems with Applications, 42(3), 1003-1012. https://doi.org/10.1016/j.eswa.2014.09.018

[9] Kayal, A. (1999). Measuring the pace of technological progress. Technological Forecasting and Social Change, 60(3), 237-245. https://doi.org/10.1016/S0040-1625(98)00030-4

[10] Chang, S. H. \& Fan, C. Y. (2016). Identification of the technology life cycle of telematics a patent-based analytical perspective. Technological Forecasting and Social Change, 105, 1-10. https://doi.org/10.1016/j.techfore.2016.01.023

[11] Haupt, R., Kloyer, M., \& Lange, M. (2007). Patent indicators for the technology life cycle development. Research Policy, 36(3), 387-398. https://doi.org/10.1016/j.respol.2006.12.004

[12] Altuntas, S., Dereli, T., \& Kusiak, A. (2015). Forecasting technology success based on patent data. Technological Forecasting and Social Change, 96, 202-214. https://doi.org/10.1016/j.techfore.2015.03.011

[13] Yoon, B. \& Park, Y. (2004). A text-mining-based patent network: Analytical tool for high-technology trend. Journal of High Technology Management Research, 15(1), 37-50. https://doi.org/10.1016/j.hitech.2003.09.003

[14] Lee, P. C., Su, H. N., \& Wu, F. S. (2010). Quantitative mapping of patented technology - The case of electrical conducting polymer nanocomposite. Technological Forecasting and Social Change, 77(3), 466-478. https://doi.org/10.1016/j.techfore.2009.08.006

[15] Chen, R., Park, J., \& Smith, A. (2014). Measuring Growth Potential of Communities in the Patent Citation Network, 111.

[16] Tseng, Y.-H. H., Lin, C.-J. J., \& Lin, Y.-I. I. (2007). Text mining techniques for patent analysis. Information Processing \& Management, 43(5), 1216-1247. https://doi.org/10.1016/j.ipm.2006.11.011

[17] Lee, S., Yoon, B., \& Park, Y. (2009). An approach to discovering new technology opportunities: Keyword-based patent map approach. Technovation, 29(6-7), 481-497. https://doi.org/10.1016/j.technovation.2008.10.006

[18] Kim, Y. G., Suh, J. H., \& Park, S. C. (2008). Visualization of patent analysis for emerging technology. Expert Systems with Applications, 34(3), 1804-1812. https://doi.org/10.1016/j.eswa.2007.01.033

[19] Choi, S., \& Jun, S. (2014). Vacant technology forecasting using new Bayesian patent clustering. Technology Analysis \& Strategic Management, 26(January 2015), 241-251. https://doi.org/10.1080/09537325.2013.850477

[20] Jun, S. (2012). A Clustering Method of Highly Dimensional Patent Data Using Bayesian Approach. International Journal of Computer Science Issues, 9(1), 7-11. Retrieved from http://ijcsi.org/papers/IJCSI-9-1-1-7-11.pdf

[21] Smojver, V., Štorga, M., \& Potočki, E. (2016). An extended methodology for the assessment of technical invention evolution. Proceedings of International Design Conference, DESIGN, DS 84, 1135-1144.

[22] Fallah, M. H., Fishman, E., \& Reilly, R. R. (2009). Forward patent citations as predictive measures for diffusion of emerging technologies. PICMET: Portland International Center for Management of Engineering and Technology, Proceedings, 420-427. https://doi.org/10.1109/PICMET.2009.5262201

[23] Seth Masia. (2016). Release! History of Safety Bindings International Skiing History Association. Retrieved September 27, 2017, from https://www.skiinghistory.org/ history/release-history-safety-bindings
[24] Cash, P., Stanković, T., \& Štorga, M. (2013). Using visual information analysis to explore complex patterns in the activity of designers. Design Studies, 35(1), 1-28. https://doi.org/10.1016/i.destud.2013.06.001

[25] Powell, W. W., White, D. R., Koput, K. W., \& Owen-Smith, J. (2005). Network Dynamics and Field Evolution: The Growth of Interorganizational Collaboration in the Life Sciences. American Journal of Sociology, 110(4), 11321205. https://doi.org/10.1086/421508

[26] Štorga, M., Mostashari, A., \& Stankovic, T. (2013). Visualisation of the organisation knowledge structure evolution. Journal of Knowledge Management, 17(5), 724 740. https://doi.org/10.1108/JKM-02-2013-0058

\section{Contact information:}

Vladimir SMOJVER, mag. ing. mech

CVH d.d.

Capraška 6, 10000 Zagreb, Croatia

University of Zagreb, Faculty of Mechanical Engineering and Naval Architecture Ivana Lučića 5, 10000 Zagreb, Croatia

vsmojver@fsb.hr

Mario ŠTORGA, prof. dr. sc.

University of Zagreb, Faculty of Mechanical Engineering and Naval Architecture Ivana Lučića 5, 10000 Zagreb, Croatia mario.storga@fsb.hr

Luleå University of Technology, Department of Business Administration, Technology and Social Sciences

97187 Luleå, Sweden

mario.storga@ltu.se

Eva POTOČKI, mag. ing. mech

University of Zagreb, Faculty of Mechanical Engineering and Naval Architecture Ivana Lučića 5, 10000 Zagreb, Croatia

epotocki@fsb.hr 